\title{
Professional Self-Realization as a Factor in the Psychological Well- Being of Specialists of Caring Professions
}

\author{
Olena D. Glavinska ${ }^{1}$, Irina M. Ovdiyenko, ${ }^{2, *}$, Oleksandra V. Brukhovetska ${ }^{3}$, \\ Tetiana V. Chausova ${ }^{3}$ and Maryna S. Didenko ${ }^{3}$
}

\begin{abstract}
${ }^{1}$ Department of Psychology and Naturel Sciences, Rivne State University of the Humanitarians, Rivne, Ukraine

${ }^{2}$ Department of Psychology and Pedagogy, Faculty of Pedagogy and Psychology, National Pedagogical Dragomanov University, Kyiv, Ukraine

${ }^{3}$ Department of Psychology and Personal Development, Educational and Scientific Institute of Management and Psychology, State Institution of Higher Education "University of Educational Management", Kyiv, Ukraine
\end{abstract}

\begin{abstract}
Research Objective: the article discusses the mutual influence of professional self-realization and the psychological well-being of specialists of caring professions. Methodology: correlation and comparative analysis in different professional groups of specialists. The study involved 465 volunteers with work experience of 3 to 40 years: teachers, doctors, medical personnel, psychologists of state and private enterprises. Several standardized self-reports were used to collect data: Ryff's Scales of Psychological Well-being, Professional Burnout Questionnaire, Kokun's Professional Self-Fulfilment Questionnaire, Gura's Workplace Satisfaction Self-assessment Survey, Tkalych's Work-Life Balance additional scale. The use of the open questions allowed clarifying some phenomenological manifestations of professional self-realization among specialists of caring professions, as well as to clarifying the external and internal determinants of self-realization. The authors tested the hypotheses about the influence of several factors on the level of psychological well-being: belonging to a certain professional group, the degree of self-realization, as well as age, gender, and length of service. The results of the study present the structure of well-being and features of self-realization in different professional groups. We proved that professional self-realization is a significant factor in the formation of individual components of psychological well-being: self-acceptance and competence. However, in some cases, high scores for professional self-realization may be associated with burnout and the desire to leave the job. The conclusions contain recommendations on organizational agency and direct psychological interventions that ensure the psychological well-being of specialists of caring professions.
\end{abstract}

Keywords: Psychological well-being, professional self-fulfilment, self-realization, burnout, work-life balance, workplace well-being.

\section{INTRODUCTION}

The study of psychological well-being in the context of the profession is of particular interest since the professional activity is the main factor in the formation of a mature personality. Skilled labour is the main type of activity in adulthood that determines the social situation of development (full inclusion of the individual in society) [1]. The connection between professional self-realization and psychological well-being seems obvious. However, there is not enough empirical data in which this relationship is specified, and their results are ambiguous. A study [2] proves the conflicting components of personality and professional development. Increasing the intensity of work in the modern world urges occupational health issues and the search for optimal work-life balance. In this aspect, the so-called "caring professions" (socionomic-type professions) are worth distinguishing. Their main

\footnotetext{
${ }^{*}$ Address correspondence to this author at the Department of Psychology and Pedagogy, Faculty of Pedagogy and Psychology, National Pedagogical Dragomanov University, Kyiv, Ukraine; Tel: +380679474717; Fax: +38 (044) 234-11-08; E-mail: irynazvarych@yahoo.com
}

purpose is to improve people's well-being by various methods and at different levels: doctors, psychologists, social workers, teachers, service specialists, etc. A high level of psychological well-being of these workers is a necessary prerequisite for the effectiveness of their professional actions [3]. But it is known that these professions are most at risk of occupational destruction due to constant stress and high density of communications. The efforts of scholars, managers, public organizations, and state institutions around the world aim to restore the psychological well-being of specialists of caring professions. The annual increase in statistics of burnout and associated problems [4, 5] indicates, however, the failure of these attempts.

The objective of this study is to determine the components and factors of influence on the experience of psychological well-being among workers of caring professions in the context of their professional selfrealization.

The results obtained will help resolve the contradictions between the understanding of subjective well-being as the main professional attribute and the 
numerous psychological problems of "providers of wellbeing" and suggest practical ways to ensure satisfaction with work and life.

\section{METHODS}

\section{Procedure}

Data were collected in the winter of 2019 in large Ukrainian cities (Dnipro, Kharkiv, Kyiv, Lviv, Rivne, Ternopil). Personnel and psychological services of enterprises, representing socionomic professions: teachers of public and private schools, doctors, medical personnel, psychologists, helped in organizing the research. Participation in the study was voluntary, the participants were guaranteed the confidentiality of the results; the obtained data were presented to the management of organizations only in a generalized form, and did not in any way affect career decisions. Independent private specialists (psychologists) were invited through the local professional communities. The selection criteria for the participants provided for at least three years of work experience.

\section{Sample Description}

The study involved 465 volunteers with work experience of 3 to 40 years. There were 177 men, 288 women; the predominance of women reflects the sociodemographic characteristics of certain professions (psychologists, nurses) - see Table 1. 296 participants represented government agencies, 169 conducted private practice, or worked in private companies.

\section{Data Collection Methods}

Ryff's Scales of Psychological Well-being was used. Well-being is seen as the perception of one's own functioning from the peak of an individual's potential.
Six components of the positive functioning of the personality were identified: positive relations with others, self-acceptance, environmental mastery, autonomy, personal growth and development, the feeling of purpose and meaning in life; their ratio determines the individual peculiarity of psychological well-being [6]. We used a culturally-specific Russianlanguage version consisting of 54 questions that respondents rated using a scale of 1 "strongly disagree" to 5 "strongly agree" (adaptations were carried out in [7]). The total of the initial values of six scales was an integral indicator of the psychological well-being of workers.

To identify the conditions opposite to well-being, the authors used the Professional Burnout Questionnaire for specialists of socionomic professions [8]. The method is a Russian-language standardized adaptation of the classic Maslach Burnout Inventory and assesses the severity of the three symptoms of burnout: emotional exhaustion, depersonalization, and reduction of personal achievements [9]. We were especially interested in the last scale, which is actually a measure of professional effectiveness: the severity of the manifestation of professional motivation, a positive attitude to the results of own work, confidence in our professional and personal competence.

For a detailed study of professional self-realization and well-being in the workplace, three methods developed by Ukrainian scholars were used:

- Kokun's Professional Self-Fulfilment Questionnaire considers self-fulfilment in the context of self-development of a personality on a life path. It contains 30 questions with 5 answer options distributed in terms of ascending severity of an attribute, where 10 questionnaire scales reflect two interrelated forms: internal and

Table 1: Composition and Description of the Sample

\begin{tabular}{|c|c|c|c|c|c|}
\hline \multirow{2}{*}{ Professional group: } & \multirow{2}{*}{ Total, N } & \multicolumn{2}{|c|}{ Distribution by gender, $\mathbf{N}$} & \multicolumn{2}{|c|}{ Age and work experience: $\min -\max , M$} \\
\hline & & women & men & age & work experience \\
\hline teachers (secondary and senior school) & 161 & 84 & 77 & $\begin{array}{c}25-65 \\
M=37.5\end{array}$ & $\begin{array}{c}3-44 \\
M=18.6\end{array}$ \\
\hline doctors of private clinic and municipal hospitals & 126 & 63 & 63 & $\begin{array}{c}26-63 \\
M=39.9\end{array}$ & $\begin{array}{c}4-44 \\
M=18.1\end{array}$ \\
\hline medical staff (nurses and ambulance attendants) & 67 & 52 & 15 & $\begin{array}{c}25-55 \\
M=33.5\end{array}$ & $\begin{array}{c}3-36 \\
M=19.8\end{array}$ \\
\hline $\begin{array}{c}\text { psychologists of state organizations (educational } \\
\text { institutions, hospitals, social services), private } \\
\text { psychologists }\end{array}$ & 111 & 89 & 22 & $\begin{array}{c}25-59 \\
M=39.3\end{array}$ & $\begin{array}{c}3-25 \\
M=13.8\end{array}$ \\
\hline
\end{tabular}


external professional self-realization. The total for the indicators of ten scales displays the general level of professional self-fulfilment [10].

- $\quad$ Gura's Workplace Satisfaction Self-assessment Survey contains 30 questions about various aspects of rofessional activity: working conditions, technological security, workload, material reward, position and informal role in the team, opportunities for professional development, the impact of work on personal life, conformity with individual interests, etc. The respondent notes the degree of satisfaction with each of the aspects, using the scale from "completely dissatisfied" to "completely satisfied" (0-4 points). The questionnaire identifies five factors that determine well-being in the workplace: 1) the organization of work: clear rules and well-functioning work processes; 2) the resource environment, social support; 3) the possibility of professional advancement and personal self-development due to the employee's active efforts; 4) involvement in the "great cause": social usefulness of work, the prestige of the profession; 5) work-life balance, the impact of work on health and other areas of individual's self-realization [11].

Tkalych's Work-Life Balance additional scale contains 10 questions with a 7-point scale aimed at clarifying the positive and negative components of the work-life balance. Positive components enrich the interaction of life spheres: social support at the workplace, support from family and friends, internal interest in work, pleasure from the process and result, ability to allocate time and resources. The imbalance is caused by irregular work schedules, overload, fatigue, lack of free time, inability to take time off or vacation at the right time [12].

All methods are published in open sources and are available for free use in scientific research.

In addition, an open question was used to collect data on professional self-realization:

1. On a scale of 0 to 100 , how much do you consider yourself realized in your profession?

2. In what specific situations of professional activity do you feel satisfied and realized?

3. What external and internal factors impede/ contribute to your professional self-realization?

\section{Data Analysis}

In interpreting the open questions, a phenomenological approach was used - we were interested in the primary wording of the answers that directly reflected the opinions and conditions of the workers. Then, using content analysis, we identified frequently occurring categories of answers that reflect the general trends of professional self-realization among representatives of socionomic professions.

When processing the results of standardized questionnaires, descriptive statistics were calculated in different professional groups, a frequency analysis was performed for individual parameters. Correlation analysis made it possible to find out the linear relationships between the components of psychological well-being and professional self-realization.

A comparative analysis was conducted for groups representing various professions: teachers $(\mathrm{N}=161)$, psychologists $(\mathrm{N}=111)$, doctors $(\mathrm{N}=126)$, and medical staff $(\mathrm{N}=67)$. For comparison of the four samples, oneway ANOVA (analysis of variance) was used (the homogeneity of the variances was pre-tested using Levene's Test). The calculations were performed using SPSS 17.0 and Microsoft Excel 2007.

\section{RESULTS}

The authors assumed that the severity of the psychological well-being of care specialists is determined by the mutual influence of two factors: belonging to a particular professional group and the degree of self-realization. We additionally tested the hypotheses about the influence of professional experience, age, and gender.

\section{Differences in Psychological Well-Being and Self- Realization in Professional Groups}

The sample presents all the options for the severity of psychological well-being - from extremely low to high; data distribution is close to normal with a slight shift to the right. There were $3.22 \%$ of respondents with low rates, indicating a pronounced dissatisfaction with themselves and their lives. At the same time, 6.02\% showed extremely high rates, $13.55 \%$ of respondents have a general indicator of psychological well-being at a level above the average.

The components with the highest average values in the sample make the main contribution to the formation of a feeling of subjective well-being of specialists of 
socionic professions - see Table 2. These turned out to be positive relationships with others (empathy, affection, intimacy, concern for the well-being of other people) and self-acceptance (positive attitude towards oneself; self-understanding, recognition of one's good and bad qualities; positive attitude to past). The Autonomy (the ability to withstand social pressure, think, and behave independently based on personal standards) had the smallest weight among the components of psychological well-being. These parameters, as well as the general severity of psychological well-being, did not differ in different professional groups.
Specific differences were revealed in the structure of the psychological well-being of specialists in different professions. Psychologists demonstrated relatively higher indicators of personal growth $(p=0.000)$; life goals prevailed among doctors $(p=0.006)$, among teachers - a sense of environmental competence $(p=0.035)$. Due to these components, representatives of different professions achieve a subjective feeling of satisfaction with life. Among the medical staff, the wellbeing was somewhat weakened due to a reduced sense of competence and control over the outside world, the inability to improve or change the surrounding circumstances.

Table 2: Descriptive Statistics in Occupational Groups (M $\pm S D)$ and Comparative Analysis

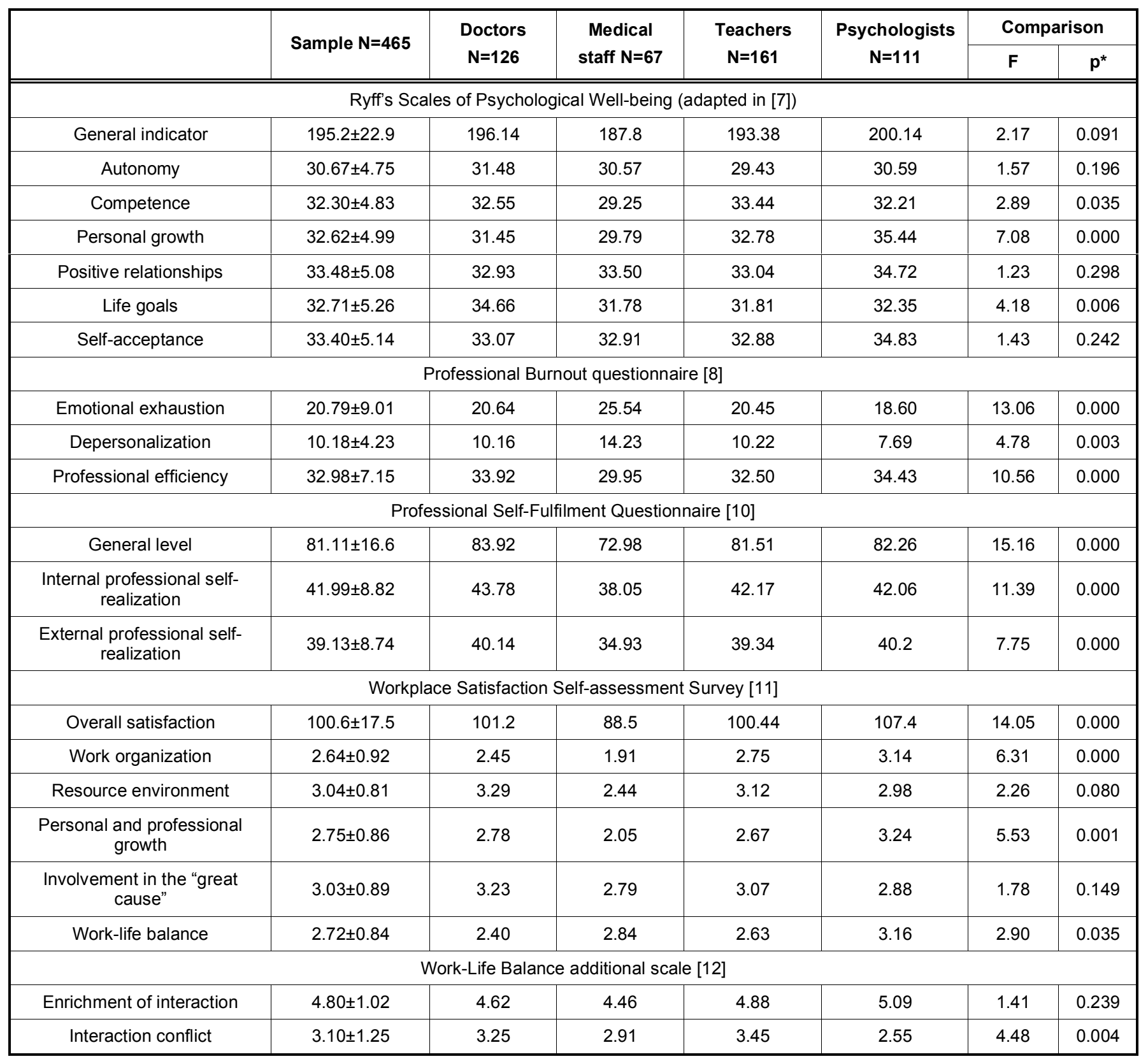


Diagnosis of professional burnout found pronounced symptoms in a third of respondents. In the whole sample, $35.05 \%$ show pronounced emotional exhaustion, in $19.13 \%$ this symptom is combined with manifestations of cynicism and dehumanizing attitudes toward subjects of their professional activity (depersonalization). In $13.98 \%$, there were changes in the structure of professional activity, loss of meaning, and a feeling of inefficiency at work. The severity of burnout symptoms varies significantly in different professional groups (see Table 2); medical staff is the most disadvantaged in this regard. Relatively high assessments of their professional performance are characteristic of psychologists and doctors.

The results of the Professional Self-Fulfilment Questionnaire allow describing the subjects as established specialists. In all groups, the internal professional component of self-realization prevailed over the external professional one. In other words, representatives of caring professions are more focused on the process of work and improve their competencies than on socially significant achievements and authority in the professional community. The highest level of professional self-fulfilment was revealed in doctors and psychologists, that is, highly qualified specialists, the lowest - in medical staff $(p=0.000)$.

The individual components of self-fulfilment are specific in different professional groups - Figure 1. For example, doctors are characterized by the highest rates of designing their own careers, satisfaction with their achievements and recognition in the professional community; but they have significantly less developed "life-profession" space than in the other groups (which can be expressed in the inability to combine work and personal life harmoniously).

Average ratings of satisfaction with working conditions significantly differ in the subsamples: the highest is among psychologists, and the lowest is among medical staff. In professional groups, differences were found for three factors: the organization of work processes $(p=0.000)$, the balance of professional and non-professional areas of life $(p=0.035)$, and the possibility of personal and professional growth in the professional environment $(p=0.001)$.

The Work-life Balance scale showed that the specifics of groups are determined by negative components that cause a conflict of interaction between different areas of life.

\section{The Phenomenology of Professional Self- Realization}

The use of the open questions allowed clarifying the external and internal determinants of professional selfrealization among caring specialists.

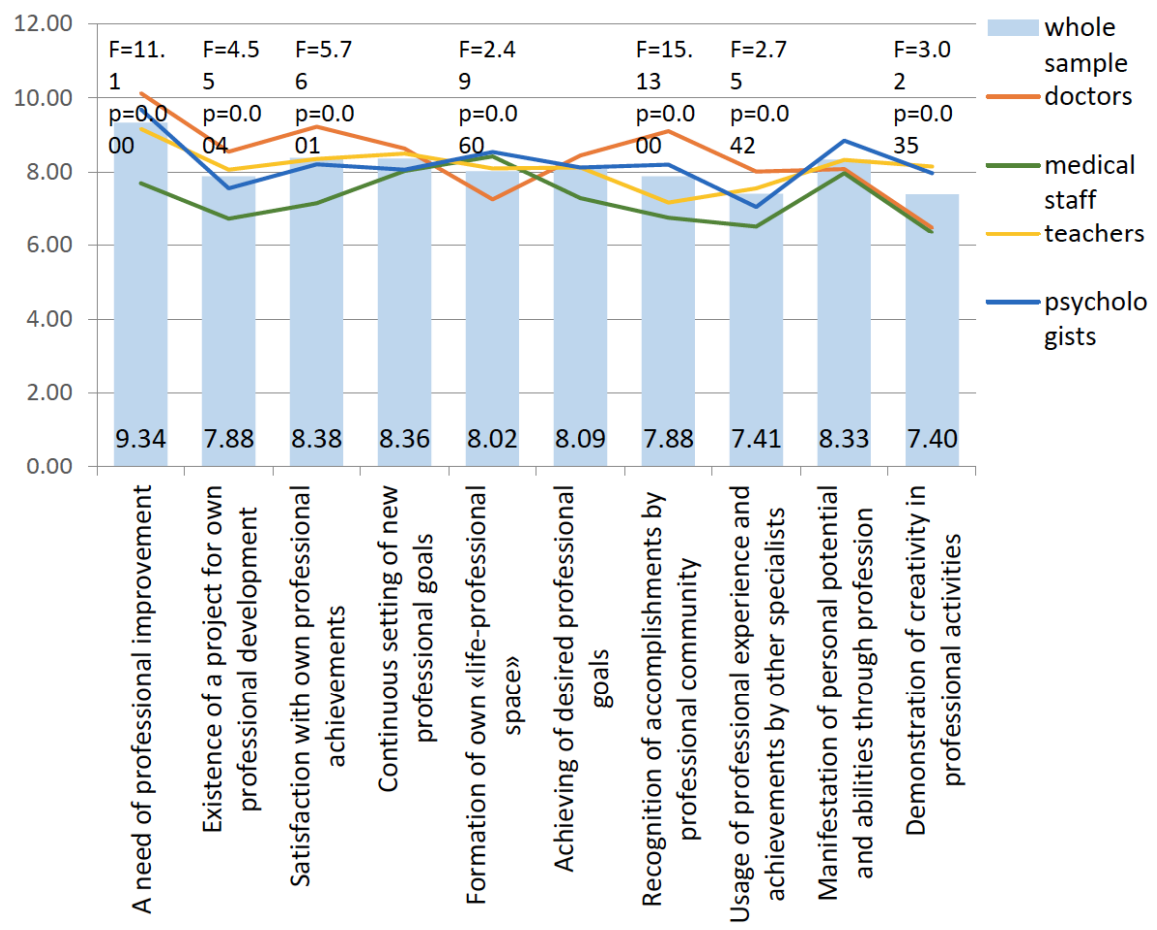

Figure 1: Average indicators of professional self-fulfilment in groups and significant results of the analysis of variance 
1. When asked about the degree of their professional realization, data were obtained in the range from 10 to $100 \%$. This indicator turned out to be closely related to age and length of service - younger participants rated their degree of professional realization lower; specialists with experience of 20 years or more gave maximum ratings. Among the groups, the highest ratings were obtained from doctors, the lowest - from psychologists.

When analysing the answers, we observed two opposite trends. On the one hand, high scores reflected job satisfaction and professional success. In some cases, the maximum score was, however, associated with overstrain, fatigue, disappointment, and other negative conditions. Respondents highly assessed the degree of their realization when they believed that they had completely exhausted themselves in the profession (for example, Doctor Alexander, 48 years old, pointedly indicated 150\%, while his burnout rates were extremely high).

2. The answers to the question about the specific experience of professional self-realization and situations in which specialists are experiencing this condition were of greatest interest. Respondents gave an average of 2-4 answers, the most popular options and their frequency are shown in Table 3.

Although the content and distribution of answers depend on the specifics of the profession, some general trends can be identified. Caring specialists feel fulfilled, first of all, when they see the real effectiveness of their own actions (for teachers, this is academic successes of pupils, for a doctor - overcoming a difficult disease, for a psychologist - improving the patient's quality of life). Awareness of self-realization is also associated with the experience of successfully solving "complex cases", socially important, and unusual tasks. The respondents feel fulfilled when they realize the high demand for their qualifications: they are sought, they are addressed in particularly difficult cases, they have been recommended to others. In other words, when "the demand for my services is even greater than my capabilities" (Irina S., Massage Therapist, 53 years old). This situation carries a hidden danger in the form of physical and emotional overload.

The expression of sincere gratitude from the subjects of their professional activity (love of children, respect of parents, gratitude of patients, etc.), as well as the official recognition of their professional skills: authority among colleagues and superiors, an invitation to public events as an expert, the use of their experience in the professional community, etc. As Table 3 shows, material awards and prizes occupy the last place in this list.

3. The participants named many external factors that impede professional self-realization, but found it difficult to name the internal determinants. $27.5 \%$ of respondents answered "nothing impedes"; other options are presented in Figure 2.

The answers often indicated a lack of time due to excessive workload (for training, professional development, implementation of the author's projects, and other activities). In this case, employees of private enterprises more often note a higher workload and a

Table 3: Distribution of Answers to the Question "In what Specific Situations of Professional Activity do you Feel Satisfied and Realized?" (\% Share) and "On a Scale of 0 to 100, how much do you Consider yourself Realized in your Profession?" (M \pm SD)

\begin{tabular}{|c|c|c|c|c|c|}
\hline Popular answer categories: & $\begin{array}{c}\text { Sample } \\
N=465\end{array}$ & $\begin{array}{c}\text { Doctors } \\
\mathrm{N}=126\end{array}$ & $\begin{array}{l}\text { Medical staff } \\
\quad \mathrm{N}=67\end{array}$ & $\begin{array}{l}\text { Teachers } \\
\mathrm{N}=161\end{array}$ & $\begin{array}{l}\text { Psychologists } \\
\quad \mathrm{N}=111\end{array}$ \\
\hline real results of professional activities & 87.74 & 91.27 & 74.63 & 88.82 & 90.09 \\
\hline successful solution of difficult tasks & 35.27 & 38.89 & 29.85 & 14.29 & 64.86 \\
\hline informal reviews and gratitude & 28.60 & 31.75 & 26.87 & 21.74 & 36.04 \\
\hline positive emotions in the process of activity & 18.06 & 8.73 & 10.45 & 31.68 & 13.51 \\
\hline $\begin{array}{c}\text { gaining new experience, expanding } \\
\text { qualifications }\end{array}$ & 16.99 & 16.67 & 25.37 & 11.80 & 19.82 \\
\hline material rewards & 13.33 & 15.08 & 22.39 & 11.18 & 9.01 \\
\hline
\end{tabular}




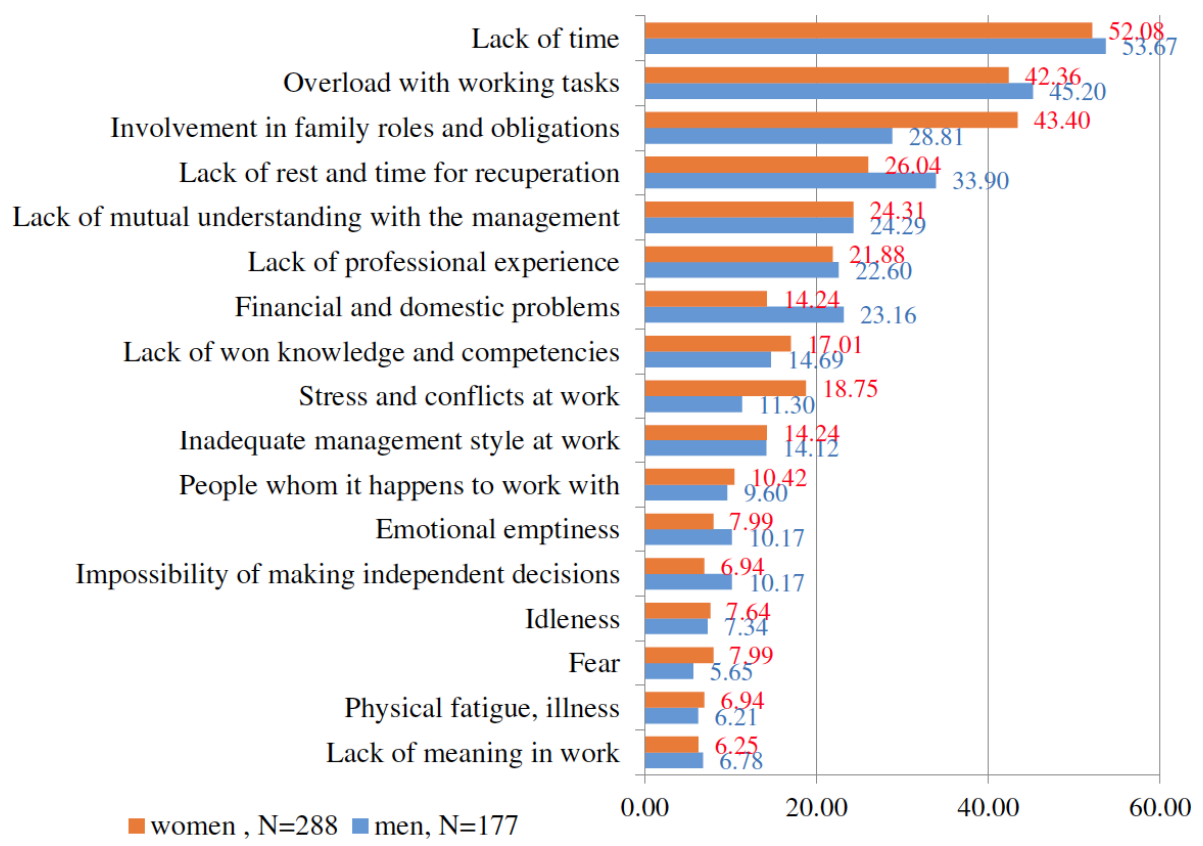

Figure 2: Possible answers to the question "What external and internal factors impede your professional self-realization?", \%

wide range of important working tasks that require urgent solutions; and employees of state enterprises complain about unnecessary (formal) duties, which are time-consuming.

Among the external factors that contribute to professional self-realization, weighty stimulation of professional growth on the part of employing organizations and support of the immediate manager (corporate training and regular certification of specialists, participation in conferences, the provision of awards and grants, recommendations for career advancement, flexible workload taking into personal account needs, etc.). The involvement of colleagues and the professional community is also very significant - different joint projects that provide the specialist with a supportive, inspiring, and developing environment - see Figure 3.

The incentives for professional self-realization must be not only in the organizational environment but also outside it. About half of the respondents noted the support of the husband/wife, other family members, and friends.

Among the internal determinants of professional self-realization, self-discipline, stress tolerance, the ability to allocate time and prioritize, persistence in

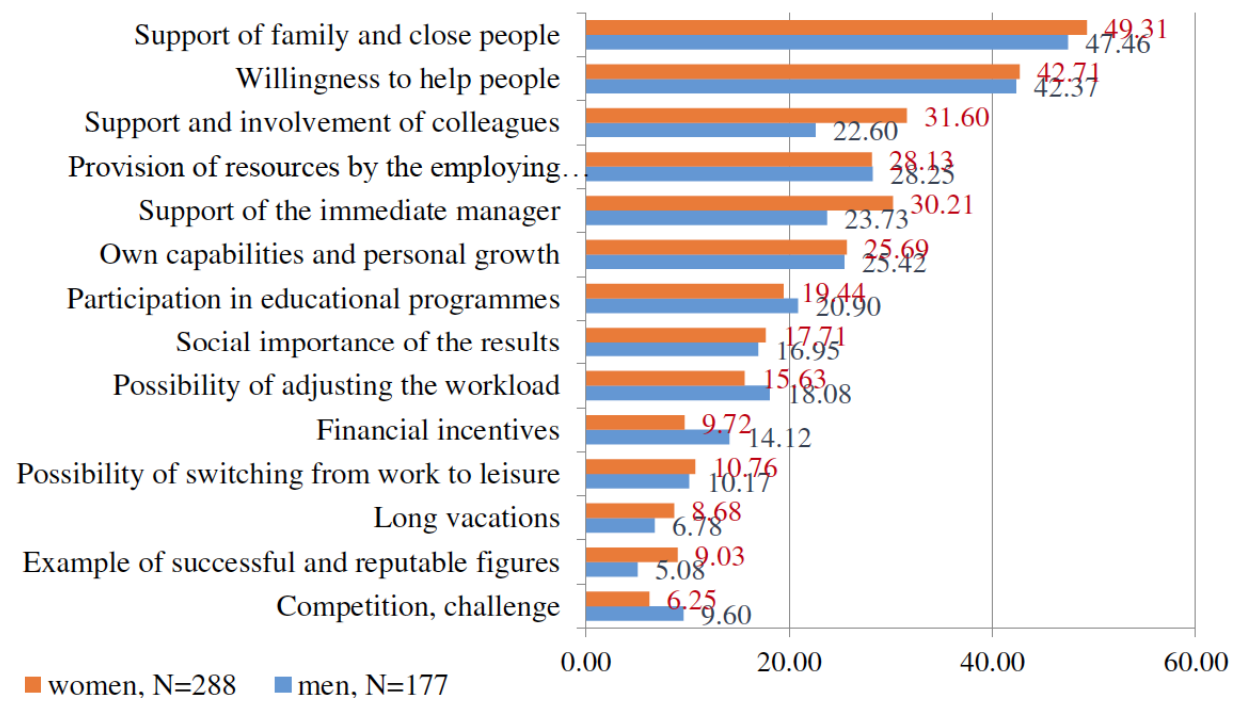

Figure 3: Answers to the question "What external and internal factors contribute to your professional self-realization?", \% 
achieving goals, and their deep interest in the profession were most frequently listed.

\section{The Relationship between Psychological Well- Being and Professional Self-Realization}

Correlation analysis (Table 4) made it possible to identify the components of professional self-realization that are linearly related to the severity of psychological well-being and its individual components.

Many parameters of the professional sphere significantly correlate with the Ryff's Scales. The index of professional performance is the most indicative - in relation to it, the strongest connections were found at the level of $p \leq 0.001$. A similar picture is demonstrated by the general indicator of self-fulfilment of the Kokun's questionnaire. Two components of well-being are most interconnected with a professional realization: selfacceptance and competence in managing the environment. The smallest number and strength of correlations are identified relative to the scales "Personal growth" and "Positive relationships".

Some of the parameters demonstrate strong and global relationships with several or all of the Ryff's Scales, indicating their important contribution to the positive functioning of the individual and the experience of life satisfaction. Among them, some variables are more determined by the external organizational environment: satisfaction with the organization of work, recognition of the achievements of a specialist by the professional community; and variables determined to a greater extent by the internal position and activity of an individual: a project of their own professional development and the constant setting of new goals; the

Table 4: Correlation Coefficients between the Components of Psychological well-being and Indicators of the Professional Sphere

\begin{tabular}{|c|c|c|c|c|c|c|c|}
\hline Diagnostic variables: & 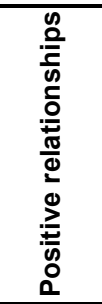 & 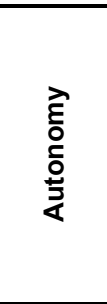 & 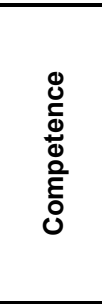 & 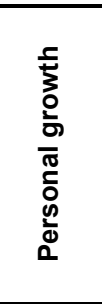 & 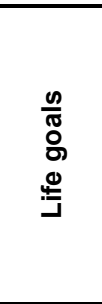 & 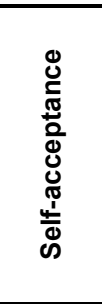 & 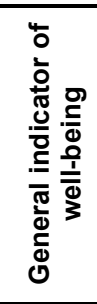 \\
\hline Age & 0.030 & -0.108 & -0.063 & -0.119 & -0.103 & -0.025 & -0.121 \\
\hline Professional experience & 0.026 & -0.104 & -0.065 & -0.144 & -0.099 & -0.031 & -0.116 \\
\hline \multicolumn{8}{|c|}{ Professional Burnout questionnaire [8] } \\
\hline Emotional exhaustion & -0.077 & -0.115 & -0.141 & -0.084 & -0.095 & -0.118 & -0.127 \\
\hline Depersonalization & -0.057 & -0.064 & -0.101 & -0.036 & -0.072 & -0.048 & -0.075 \\
\hline Professional efficiency & 0.132 & 0.143 & $\underline{0.176}$ & 0.150 & 0.166 & 0.134 & $\underline{0.183}$ \\
\hline \multicolumn{8}{|c|}{ Professional Self-Fulfilment Questionnaire [10] } \\
\hline Level of internal professional self-fulfilment & 0.111 & 0.108 & 0.110 & 0.087 & .107 & 0.148 & 0.136 \\
\hline Level of external professional self-fulfilment & 0.097 & 0.133 & 0.124 & 0.094 & .091 & 0.152 & 0.139 \\
\hline General level of self-fulfilment & 0.114 & 0.128 & 0.125 & 0.097 & .109 & $\underline{0.162}$ & 0.148 \\
\hline \multicolumn{8}{|c|}{ Workplace Satisfaction Self-assessment Survey[11] } \\
\hline Overall satisfaction & 0.039 & 0.069 & 0.105 & 0.043 & 0.074 & 0.112 & 0.089 \\
\hline Work organization & 0.070 & 0.106 & 0.109 & 0.067 & 0.096 & 0.104 & 0.111 \\
\hline Resource environment & 0.087 & 0.100 & 0.125 & 0.033 & 0.083 & 0.097 & 0.104 \\
\hline Personal and professional growth & 0.046 & 0.119 & 0.126 & 0.119 & 0.150 & 0.115 & 0.138 \\
\hline Involvement in the "great cause" & 0.045 & 0.016 & 0.097 & -0.009 & 0.020 & 0.085 & 0.049 \\
\hline Work-life balance & 0.070 & 0.117 & 0.130 & 0.116 & 0.131 & 0.150 & 0.146 \\
\hline \multicolumn{8}{|c|}{ Work-Life Balance additional scale [12] } \\
\hline Conflict of interaction & -0.067 & -0.105 & -0.121 & -0.084 & -0.097 & -0.091 & -0.123 \\
\hline
\end{tabular}

Note: The critical values of the Pearson correlation coefficient are 0.092 at $p \leq 0.05,0.121$ at $p \leq 0.01,0.155$ at $p \leq 0.001$. 


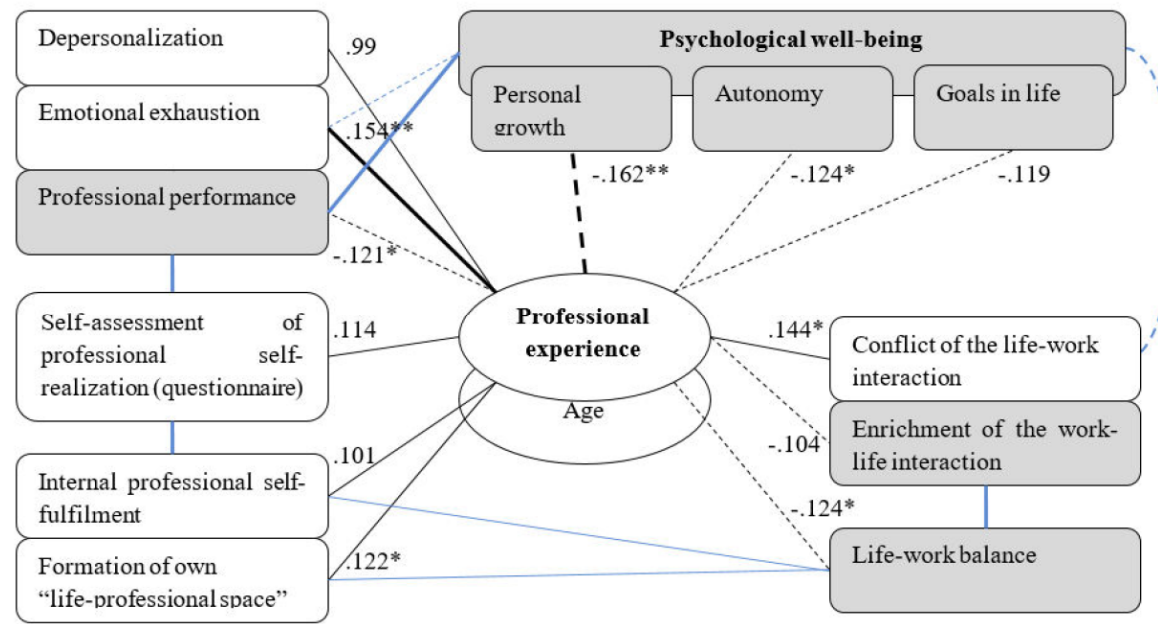

Figure 4: The nature of the correlations between indicators of professional experience, components of psychological well-being and professional self-realization.

Note: solid lines show direct correlations, dashed lines - inverse correlations; correlation strength is reflected by the thickness ( ${ }^{*}$ correlation significance $\left.\mathrm{p} \leq 0.01,{ }^{* *} \mathrm{p} \leq 0.001\right)$.

possibility of personal and professional growth, lack of emotional exhaustion.

With increasing age and work experience, the severity of psychological well-being significantly decreases. This may be due to worsening health, as well as the accumulation of symptoms of professional burnout. In addition, we analysed the correlations of professional experience and age with self-realization indicators - Figure 4. The relationships obtained are paradoxical - professional effectiveness and selfrealization have opposite signs, although these parameters directly correlate with each other.

With age, the imbalance of different spheres of life becomes more acute, the symptoms of professional burnout accumulate, and overall the severity of the experience of psychological well-being decreases. At the same time, a mature person successfully forms "own professional and living space" and generally highly evaluates own fulfilment. It is important to understand that a high assessment of self-fulfilment, in this case, may indicate the exhaustion of personal resources and the intention to leave the profession.

\section{DISCUSSION}

The close correlations between indicators of psychological well-being and professional selfrealization raise the question of cause-effect relationships. On the one hand, professional activity determines the formation of traits of adult personal. Professional self-fulfilment is traditionally regarded as a factor in ensuring an employee's mental health, which certainly has a positive effect on all aspects of his wellbeing [13]. On the other hand, success in caring professions is unthinkable if the person himself is psychologically disadvantaged. The third option of joint formation is also possible; the correspondence of the pace of personal and professional development conditions "the fulfilment by a person of himself" [1].

Most socionomic professions require a pronounced prosocial orientation, self-confidence, activity, love of life, and other people. Therefore, psychological wellbeing is an integral part of the professional self-concept of caring specialists, primarily psychologists, for whom this is an element of a "professional personal myth" [14]. It can be assumed that caring specialists may consciously hide or unconsciously deny the existing illbeing, considering such problems a sign of professional inadequacy and personal incompetence. Earlier, in [15], occupational therapists may fail to balance work and personal life due to "the pressures of the neoliberal workplace". Our study showed that high self-esteem of professional realization could not be considered unambiguous evidence of psychological well-being. In some cases, it is a marker of opposing conditions - burnout and frustration. This result confirms that burnout and enthusiasm for work (vigour, dedication, absorption) are not opposite phenomena and can exist independently [16].

The obtained results confirmed the significance of the burnout problem for specialists in caring professions. A long-term solution to this problem may be creating a culture of "self-care" even at the stage of professional training $[17,18]$. 
Today, the well-being of employees is recognized as the top priority and resource of any organization. Professional communities, together with research institutes, regularly monitor the health and psychological state of employees. Conceptual models have been developed to help organizations provide workplace well-being, balance workloads and avoid burnout: Conservation of Resources model [19], the Areas of Worklife model [20], Stanford WellMD Professional Fulfilment Model [21]; their strengths and weaknesses are actively discussed [22, 23]. However, Ukrainian specialists work in different corporate cultures. Natural professional crises are exacerbated by unfavourable socio-economic conditions. The paper describes external conditions that stimulate and inhibit the professional self-realization of caring specialists.

The component structure of psychological wellbeing with a predominance of positive relationships, self-acceptance, and ignoring autonomy can be explained by professional specifics, which involve constant communication with people and assisting. It should be noted that most of the previous studies in large samples using the Ryff's model demonstrated the predominance of the parameter "Positive relations with others" [6, 7, 24-26]; all other components varied different cultural, age and gender groups. Positive relations are a universal human factor in well-being; its correlation with professional self-realization is minimal.

It is known that indicators "Personal growth" and "Life goals" are significantly reduced in older age groups - here, our results completely coincide with the data of previous studies $[25,26]$. This fact can be explained by the transition to new stages of professional and personal development. With age, the achievement of the main life goals actualizes other aspects of self-fulfilment. This explains the negative correlations of age and length of service with the worklife balance; since values and meanings that lie outside the professional sphere become more relevant for a mature personality (family, civic activity, health, spirituality, etc.).

This leads to reflection on how the state of satisfaction or dissatisfaction stimulates an individual's activity, including professional activity. On the one hand, satisfaction accompanies professional success. At the same time, internal dissatisfaction (with oneself, with the results of activities, external circumstances, etc.) encourages activity that allows constructing the desired social context and leads to professional and personal growth [2]. Therefore, people quite satisfied with themselves rarely find themselves at the top of professionalism; progress is ensured by adequately low self-esteem, which initiates a feeling of dissatisfaction even against the background of real achievements [27]. In a study [28] was written about the need for a "specific contradictory state", which combines satisfaction from existing achievements and deficiency in their assessment (the vision of imperfections stimulates the desire to do something better). A person evaluates his life with the help of subjective standards; usually, there is "a gap between what a person is and what he can and wants to be" [26]. We should also recall Maslow's theory [29], according to which the motivation for development is unsaturated - achieving success does not weaken it, but rather encourages new achievements.

Given the empirical results obtained and the theoretical interpretations that explain them, we can say that professional self-realization of caring specialists is based on the internal motives, needs, and values of an individual. First of all, this is a prosocial orientation, which is expressed in the desire to help other people and see a positive result of their own actions.

\section{CONCLUSIONS}

Profession determines the severity and specific forms of self-realization of an individual, as well as a general level and the structure of psychological wellbeing. The highest level of professional self-fulfilment was revealed in doctors and psychologists, that is, highly qualified specialists, the lowest - in medical staff. A high level of psychological well-being of workers in caring professions is achieved due to the severity of the components "positive relations with other people" and "self-acceptance".

Individual components of self-realization more than others correlate with the positive functioning of a personality. They include variables regulated by the organizational environment (satisfaction with the organization of work processes, recognition of the achievements of a specialist by the professional community) and variables regulated by the subject: activity aimed at personal and professional growth. Two components of well-being are most interconnected with a professional realization: self-acceptance and competence. With age, the mechanisms of professional self-fulfilment change: the sense of self-effectiveness decreases, but the sense of fulfilment increases, which can be explained by the restructuring of the value hierarchy after 40 years. 
Representatives of socioniomic professions are dominated by internal professional forms of selfrealization, aimed at self-designing and improving their competencies. External professional self-realization is secondary and less subjectively significant. Workers experience fulfilment primarily when they see the real effectiveness of their own efforts to ensure the wellbeing of other people. Internal stimulation helps to successfully overcome the lack of external resources, to find opportunities for self-realization in different life conditions. The optimal gap between the tasks set and the means available for their implementation providesmotivation for self-development, without leading to existential conflicts. Social support and reinforcement of professional successes in a specific organizational environment make it possible to realize the personal potential and achieve the highest selffulfilment.

\section{RECOMMENDATIONS}

Satisfaction with working conditions is determined by the competent organization of work processes and a clear distribution of functions. Own activity aimed at personal and professional growth and supported by organizational resources is important. Workers are sensitive to the imbalance of work and other areas of personal, family, social life, to a lack of time and resources. In the workplace, ill-being can be partially compensated by social support from management, colleagues, and loved ones, as well as through the experience of involvement in a great cause, social usefulness, and the importance of their work.

Support to the well-being of caring specialists includes various organizational changes: expanding professional capabilities, balancing workload, creating an appropriate remuneration system, providing social support, and other conditions for employees to fulfil their needs while maintaining their physical and mental health. In individual psychological interventions, it is important to timely resolve internal and interpersonal conflicts, reflect on internal resources in each professional situation, use the opportunities of external (social and organizational) support, and verify the reality of one's professional ideals and external requirements. The balance of different life spheres, the formation of a self-care culture, and the formation of a professional position of a "provider of psychological well-being" will allow avoiding professional burnout and preserving productivity for a long time.

\section{ACKNOWLEDGEMENT}

We express our sincere gratitude to the heads of universities and departments: Rivne State University of the Humanitarians, Department of Psychology and Pedagogy (NPU Dragomanov, Kyiv), Educational and Scientific Institute of Management and Psychology (University of Educational Management, Kyiv), for a hospitable research environment. We would like to thank Natalia Gura for kindly provided author's diagnostic tool. This work would not have been possible without the respondents - helping specialists who sincerely shared their professional and personal experiences. Thanks to the reviewers and editors of the Journal of Intellectual Disability: Diagnosis and Treatment for invaluable advice in preparing this article.

\section{REFERENCES}

[1] Bodalev AA. The pinnacle of adult development: characteristics and conditions of achievement. Moscow: Flint Nauka; 1998

[2] Bogatyreva OO, Martsinkovskaya TD. Professional selfactualization in the field of personality development. Psikhologicheskie Issledovaniya 2009; 1(3). [cited 2020 May 9]. Available from: http://psystudy.ru/index.php/num/2009n13/53-bogatyreva3.htm

[3] Bochelyuk V. Psychological peculiarities of professionalactivity potential of the individual. Scientific Bulletin of KSU Series Psychological Sciences 2016; 1(4): 138-43.

[4] Stehman CR, Testo Z, Kellogg AR. Burnout, drop out, suicide: Physician loss in emergency medicine, Part I. Western Journal of Emergency Medicine 2019; 20(3): 48594

https://doi.org/10.5811/westjem.2019.4.40970

[5] CIPD. Health and well-being at work: Survey report 2020 London: Chartered Institute of Personnel and Development; 2020.

[6] Ryff CD. Psychological well-being in adult life. Current Directions in Psychological Science 1995; 4(4): 99-104. https://doi.org/10.1111/1467-8721.ep10772395

[7] Zhukovskaya LV, Troshikhina EG. K. Ryff's scale of psychological well-being. Psikhologicheskiľzhurnal2011; 32(2): 82-93.

[8] Vodopyanova NE, Starchenkova ES, Nasledov AD. Standardized questionnaire "Professional burnout" for specialists in socionomy professions. Bulletin of St. Petersburg University. Series 12: Psychology. Sociology. Pedagogy 2013; 4: 17-27.

[9] Maslach C, Jackson S. The measurement of experienced burnout. Journal of Occupational Behavior 1981; 2(2): 99113 https://doi.org/10.1002/job.4030020205

[10] Kokun OM. Questionnaire of professional self-realization Practical psychology and social work 2014; 7: 35-9.

[11] Gura NA. Career satisfaction as a career development and social and occupational mobility factor. Organizational psychology. Economic psychology 2019; 2-3(17): 35-47. https://doi.org/10.31108/2.2019.3.17.4

[12] Tkalych MH. The "work - life" balance of personnel: the substantiation of empirical indicators. Problems of Modern Psychology 2017; 1(11): 85-90. 
[13] Malimon L. Professional self-realiazation as mental health factor of public service personell. Psychological Prospects Journal 2018; 31: 195-206.

https://doi.org/https://doi.org/10.29038/2227-1376-2018-31195-206

[14] Kulkina UN, Kozlovskaya NV. Psychological well-being as a component of the professional personality myth of university students. In: Vodyakha SA, editor. The psychological wellbeing of modern man. Yekaterinburg: USPU; 2018: p. 320-8.

[15] Clouston TJ. Whose occupational balance is it anyway? The challenge of neoliberal capitalism and work-life imbalance. British Journal of Occupational Therapy 2014; 77(10): 50715.

https://doi.org/10.4276/030802214X14122630932430

[16] Schaufeli WB, Bakker AB. Job demands, job resources and their relationship with burnout and engagement: a multisample study. Journal of Organizational Behavior2004; 25(3): 293-315.

https://doi.org/10.1002/job.248

[17] Wise EH, Hersh MA, Gibson CM. Ethics, self-care and wellbeing for psychologists: Reenvisioning the stress-distress continuum. Professional Psychology: Research and Practice 2012; 43(5): 487-94.

https://doi.org/10.1037/a0029446

[18] Zahniser E, Rupert PA, Dorociak KE. Self-care in clinical psychology graduate training. Training and Education in Professional Psychology 2017; 11(4): 283-89. https://doi.org/10.1037/tep0000172

[19] Hobfoll SE. Conservation of resources. A new attempt at conceptualizing stress. American Psychologist 1989; 44(3): 513-24. https://doi.org/10.1037/0003-066X.44.3.513

[20] Leiter MP, Maslach C. Areas of worklife: a structured approach to organizational predictors of job burnout. In:
Perrewe PL, Ganster DC, editors. Research in occupational stress and well-being. Oxford: Elsevier; 2004: p. 91-134.

[21] Trockel M, Hamidi M, Murphy ML, de Vries PP, Bohman B. 2016 Physician wellness survey: Full report. Stanford Medicine 2017. [cited 2020 May 9]. Available from: https://wellmd.stanford.edu/content/dam/sm/wellmd/documen ts/Full-2016-Physician-Wellness-Survey-Report-16-Aug2017-Final-rd.pdf

[22] Maslach C, Leiter MP. Understanding the burnout experience: recent research and its implications for psychiatry. World Psychiatry 2016; 15(2): 103-11. https://doi.org/10.1002/wps.20311

[23] Stewart MT, Reed S, Reese J, Galligan MM, Mahan JD. Conceptual models for understanding physician burnout, professional fulfillment, and well-being. Current Problems in Pediatric and Adolescent Health Care 2019; 49(11): 100658. https://doi.org/10.1016/j.cppeds.2019.100658

[24] Hrubyak OM. Psychological well-being of the individual in early adulthood. Doctoral dissertation. Chernivtsi; 2015.

[25] Bocheliuk VY. Structure of psychological welfare and its role in making life through different periods of adulthood. Theoretical and applied problems of psychology 2020; 1(51): 17-33.

https://doi.org/10.33216/2219-2654-2020-51-1-17-33

[26] Shevelenkova TD, Fesenko PP. Psychological well-being of an individual (review of basic concepts and research methodology). Psychological Diagnostics 2005; 3: 95-121.

[27] Zeer EF. Psychology of professional development. Moscow: Academy; 2007.

[28] Kokun OM. Life and professional self-realization as a subject of research of modern psychology. Practical Psychology and Social Work 2013; 9: 1-5.

[29] Maslow AH. The farther reaches of human nature. New York: Penguin Press; 1972.

Received on 02-07-2020

Accepted on 31-07-2020

Published on 14-09-2020

\section{DOI: https://doi.org/10.6000/2292-2598.2020.08.03.32}

(C) 2020 Glavinska et al.; Licensee Lifescience Global.

This is an open access article licensed under the terms of the Creative Commons Attribution Non-Commercial License (http://creativecommons.org/licenses/by-nc/3.0/) which permits unrestricted, non-commercial use, distribution and reproduction in any medium, provided the work is properly cited. 